DOI: $10.21767 / 2472-1158.100020$

\title{
Psychiatric Epigenetics: A Personal Perspective
}

\author{
Jacob Peedicayil* \\ Department of Pharmacology and Clinical Pharmacology, Christian Medical College, Vellore, India
}

*Corresponding author: Jacob Peedicayil, Department of Pharmacology and Clinical Pharmacology, Christian Medical College, Vellore, India, Tel: +91-0416-2284237; Fax: Fax: +91-416-2284237; E-mail: jpeedi@cmcvellore.ac.in

Received date: May 30, 2016; Accepted date: June 02, 2016; Published date: June 04, 2016

Citation: Peedicayil J. Psychiatric Epigenetics: A Personal Perspective. J Clin Epigenet. 2016, 2:2

\section{Editorial}

Based on reading two popular science books by the noted Kenyan anthropologist Richard Leakey[1,2], I hypothesized in 2001 and 2002 that psychiatric disorders like schizophrenia (SZ), bipolar disorder (BD) and major depressive disorder (MDD), are due to epigenetic, rather than genetic, defects $[3,4]$. In these two books, Leakey discussed how humans evolved in Africa, widely thought to be the "cradle" of mankind. The emphasis of these books was on the evolution of the human brain and mind. The books suggested that during the history of life on earth, after the origin of life, and the origin of multicellular organisms, the origin of human consciousness, linked with the evolution of the human brain and mind, was the third major revolution. Leakey suggested that our ancestors, like other primates, were quintessentially social creatures. In primate societies, the challenge for individuals is to predict the mind and behaviour of others. If individuals were able to monitor their own behaviour, they would have developed a sense of what to do in different situations. This monitoring ability is one definition of consciousness, and would have conferred a great evolutionary advantage to those individuals who possessed it. Once consciousness was established, there would have been a positive selection of individuals well-endowed with it since it would have favoured survival. In due course, over a large number of generations, this would have led to an increase in size of the brain, development of the mind, increased intelligence, and sharpened self-awareness. Leakey suggested that these events probably occurred over the last 2.5 million years. At the time of reading these two books I was interested in the genetics of psychiatric disorders like SZ, BD, and MDD. On reading these two books, I intuitively gathered that such psychiatric disorders have a non-genetic, rather than a genetic, basis. On looking up the scientific literature I came across a concept I had not heard of before, namely, epigenetics. At that time epigenetics was commonly defined as "the study of heritable changes in gene expression not involving changes in DNA sequence". I hypothesized that psychiatric disorders like $\mathrm{SZ}, \mathrm{BD}$, and MDD are epigenetic disorders due to heritable defects in gene expression not due to changes in DNA sequence, that is, they are due to epimutations $[3,4]$. Later on, based on epigenetic studies in rodents [5,6], I suggested that psychosocial factors act via epigenetic mechanisms in the pathogenesis of psychiatric disorders [7].
In retrospect, how has this theoretical research in psychiatric epigenetics fared in the light of experimental evidence?. At the turn of this century, when this theoretical work was initially published, there was very little experimental evidence to support it. However, over the past 15 years, the case for a role for epigenetics in the pathogenesis of psychiatric disorders like SZ, BD, and MDD has become increasingly solid. For example, in SZ and BD the promoters of the RELN and glutamic acid decarboxylase 1 (GAD1) genes are thought to be hypermethylated in the prefrontal cortex [8]. In MDD, the brain-derived neurotrophic factor (BDNF) gene is thought to be hypermethylated both in the prefrontal cortex and in peripheral blood [9]. In addition to DNA methylation, there is increasing evidence that noncoding RNAs like microRNAs (miRNAs) and histone modifications are dysregulated in these disorders $[10,11]$. The suggestion that psychosocial factors act via epigenetic mechanisms to lead to psychiatric disorders [7] has been supported by experimental evidence by numerous epigenetic studies on humans [12-14]. Compared to epigenetic studies on psychiatric disorders like $\mathrm{SZ}, \mathrm{BD}$, and MDD, genetic mapping studies of these disorders have been less successful, with no genetic mutation or polymorphism predisposing to these disorders having been definitively identified to date [15]. In addition to SZ, BD, and MDD, even other psychiatric disorders like Alzheimer's disease, intellectual disability, and autism spectrum disorders are now known to have an epigenetic role in their pathogenesis $[16,17]$. To conclude, as is well known, the study of the inheritance of psychiatric disorders involves the the most complicated aspects of the entire gamut of biology and medicine [18]. The study of the inheritance of psychiatric disorders cuts across scientific boundaries and can be approached from diametrically opposite vantage points. Psychiatric disorders have not readily revealed their secrets for more than a century and continue to conceal their secrets. In this context, epigenetics may well hold the keys to unlocking the mysteries of psychiatric disorders.

\section{Conflicts of Interest}

$\mathrm{Nil}$ 


\section{References}

1. Leakey R (1992) Origins Reconsidered. In Search of What Makes us Human. Doubleday: New York.

2. Leakey R (1994) The Origin of Humankind. Phoenix: London.

3. Peedicayil J (2001) The importance of cultural inheritance. Med Hypotheses; 56: 158-159.

4. Peedicayil J (2002). The importance of cultural inheritance in psychiatric genetics. Med Hypotheses 58: 164-166.

5. Weaver IC, Cervoni N, Champagne FA, D' Alessio AC, Sharma S, et al (2004) Epigenetic programming by maternal behaviour. Nat Neurosci 7: 847-854.

6. Tsankova NM, Berton O, Renthal W, Kumar A, Neve RL, et al (2006) Sustained hippocampal chromatin regulation in a mouse model of depression and antidepressant action. Nat Neurosci 9: 519-525.

7. Peedicayil J (2008) Psychosocial factors may act by epigenetic mechanisms in the pathogenesis of mental disorders. Med Hypotheses 70: 700-701.

8. Grayson DR, Guidotti A (2013) The dynamics of DNA methylation in schizophrenia and related psychiatric disorders. Neuropsychopharmacology 38: 138-166.

9. Duclot F, Kabbaj M (2015) Epigenetic mechanisms underlying the role of brain-derived neurotrophic factor in depression and response to antidepressants. J Exp Biol 218: 21-31.
10. Issler O, Chen A (2015) Determining the role of microRNAs in psychiatric disorders. Nat Rev Neurosci 16: 201-112

11. Abdolmaleky HM, Zhou JR, Thiagalingam S (2015) An update on the epigenetics of psychotic diseases and autism. Epigenomics 7: 427-449.

12. McGowan P, Sasaki A, Huang TC, Unterberger A, Suderman M, et al (2009) Promoter-wide hypermethylation of the ribosomal RNA gene promoter in the suicide brain. PLoS One 3: e2085

13. McGowan P, Sasaki A, D'Alessio AC, Dymov S, Labonte B, et al (2009) Epigenetic regulation of the glucocorticoid receptor in human brain associates with childhood abuse. Nat Neurosci 12: 342-348.

14. Labonté B, Azoulay N, Yerko V, Turecki G, Brunet A (2014) Epigenetic modulation of glucocorticoid receptors in posttraumatic disorder. Transl Psychiatry 4: e368.

15. Leo J (2016) The search for schizophrenia genes. Issues Sci Technol Winter 68-71.

16. van Bokhoven $H$ (2011) Genetic and epigenetic networks in intellectual disabilities. Annu Rev Genet 45: 81-104.

17. Coppedè $F$ (2014) Epigenetics and Cognitive Disorders. In: Epigenetics in Psychiatry Elsevier: Waltham. MA: 343-368.

18. Lipowski ZJ (1989). Psychiatry: mindless or brainless, both or neither? Can J Psychiatry 34: 249-254. 